\title{
MERINOS Y TENENTES EN EL «TERRITORIVM LEGIONENSE»: UNA APORTACIÓN AL ESTUDIO DE LA ORGANIZACIÓN TERRITORIAL DE LOS REINOS OCCIDENTALES ${ }^{1}$
}

\author{
Julia MONTENEGRO VALENTÍN \\ Universidad de Valladolid
}

Es evidente que la organización territorial durante la alta y plena Edad Media, como cualquier otro problema histórico, es susceptible de ser estudiada desde enfoques muy dispares. Y seguramente por esta razón no todos los historiadores que han dedicado su atención a estos temas coinciden en sus apreciaciones al respecto.

Desde nuestro punto de vista, para poder llegar a una visión global de la organización territorial en los reinos occidentales es preciso previamente llevar a cabo un análisis pormenorizado de cada uno de los distritos: momento de su aparición, límites geográficos y la estabilidad o inestabilidad de los mismos, ubicación geográfica (si tiene o carece de límites naturales bien definidos, su mayor o menor proximidad al centro neurálgico del Reino, su mayor o menor proximidad a la frontera) y en qué medida estos condicionantes pudieron influir en las características del distrito; su evolución a medida que avanza la frontera, aumenta la complejidad de la administración del Reino y se introducen nuevas corrientes; personajes que ostentan su gobierno, analizando su relevancia política y social, sus orígenes familiares, etc., pues sólo de esta forma se podrán establecer con certeza cuestiones tan importantes como, por ejemplo, si el

1 Texto enviado en su momento para su publicación en el Homenaje a la Prof. E. García (Universidad de Oviedo). Pero, puesto que ni nos pidieron soporte informático ni nos han enviado pruebas de imprenta, la edición está lejos de nuestra total satisfacción, por lo que hemos optado por publicarlo nuevamente. Por lo demás, este trabajo ha sido elaborado en el marco del Proyecto no PB96-0264C03-02, financiado por la DGICYT. 
titular de un distrito podía serlo sin disponer de una base patrimonial previa en el mismo, o si era habitual la vinculación entre ejercicio de poder político y arraigo en la comarca, y su capacidad (o incapacidad) de consolidar el cargo en el linaje, así como si simultáneamente controlaban otros distritos (colindantes o no) u ostentaban otros cargos.

Todo ello partiendo de un análisis crítico de las fuentes documentales. No es posible otorgar la misma credibilidad a un documento original que a una copia, siempre susceptible de contener errores, cuando no manipulaciones, de toda índole: en la datación, en la transcripción de nombres propios, etc. Y para los datos que ahora nos interesan, tampoco podemos otorgar el mismo valor a un documento privado que a un diploma real, pues obviamente éstos tenderán a ser mucho más precisos a la hora de reflejar la situación de la organización territorial, en un determinado momento o en un determinado territorio, que aquéllos, que en ocasiones ofrecen una visión excesivamente localista de la realidad?

La tarea es ardua por cuanto para los primeros siglos de la Edad Media los testimonios son escasos, y cuando éstos proliferan - en términos generales a partir del siglo XI- la creciente complejidad de la organización territorial no siempre queda bien reflejada en los textos. El fenómeno se agudiza notablemente en el siglo XII. Una primera lectura de los documentos de estos años puede incluso hacer pensar en una situación caótica. Pero una relectura de los datos obtenidos - cotejándolos, cuando ello sea posible, con los que puedan proporcionar las colecciones diplomáticas reales o de territorios limítrofes- permite clarificar notablemente el panorama, pues de ella se hace evidente que, a la indudable complejidad de la organización territorial, se unen otros hechos, como la costumbre de consignar a un personaje al frente de una tenencia sin especificar que tal personaje gobernaba «sub manu» del verdadero titular de la misma ${ }^{3}$, siendo aquél un mero delegado del magnate que por ostentar la titularidad de un gran número de tenencias, muchas veces dispersas, no podía controlar directamente todos los distritos bajo su mando. Todo ello sin olvidar que los titulares de tenencias con frecuencia ejercían simultáneamente algún importante cargo en la corte y que, como ya hemos manifestado anteriormente ${ }^{4}$, paulatinamente el cargo de tenente quedó en buena medida vacío de contenido.

Estimamos que sólo con este análisis pormenorizado de cada uno de los distritos se podrá efectuar posteriormente un estudio comparativo entre los mismos, para de

2 Es el caso, entre otros, de una mención datada en 1155 al gobierno del conde Osorio, sin duda Osorio Martínez, en Cotanes; cfr. Colección diplomática del monasterio de Sahagún (857-153), IV, ed. J.A. FERNÁNDEZ FLÓREZ, León, 1994, doc. nº 1322 (= Colección Sahagún).

3 Así, por ejemplo, en 1162 se consigna: «lohanne Martini, sub manu domni Poncii de Minerua, turres Legionis tenente», pero en 1164 se menciona únicamente a Juan Martín como “...turres Legionis tenente", sin indicar su subordinación a Ponce de Minerva; cfr. Colección documental de la catedral de León, V, ed. J.Ma FERNÁNDEZ CATÓN, León, 1993, doc. no 1517 y 1531 (=Colección León).

4 J. MONTENEGRO, «La administración territorial en San Román de Entrepeñas, Saldaña y Carrión durante la Plena Edad Media (1074-1252)", Actas del /I Congreso de Historia de Palencia, IV, Palencia, 1990, pp. 348 ss. 
esta forma poder obtener una visión de conjunto de lo que fue la organización territorial de los reinos occidentales durante la Alta y Plena Edad Media.

Con arreglo a estas premisas vamos a abordar algunos aspectos relativos al «territorium legionense».

\section{EL «TERRITORIUM LEGIONENSE»}

"Territorium» es un término hasta cierto punto genérico. Es indudable que muchas veces es sinónimo de distrito, pero no siempre ocurre así; también se utiliza esta expresión para designar un ámbito territorial caracterizado por algún accidente geográfico, como puede ser un valle, o delimitado por el curso de dos ríos 5 . Así se explica que, en ocasiones, determinados lugares, que, sin lugar a dudas, formaron parte de un distrito, aparezcan a su vez caracterizados como "territoria» 6 .

En el caso concreto que ahora nos ocupa hemos podido constatar cómo con el término "territorium legionense» se designa, en efecto, un distrito, pero con tal expresión, o la de «terra Legionis», se alude también a otras realidades muy distintas. Estimamos verosímil que, al convertirse la ciudad de León desde principios del siglo $\mathrm{X}$ en centro neurálgico del Reino, fuera entonces la expresión «territorium legionense» genérica, y aludiera, sin mayores precisiones, a las tierras situadas en el entorno de la sede regia. Sí es posible detectar en estos primeros momentos la percepción del "territorium legionense» como algo distinto de Galicia y Asturias; serían en general las tierras situadas al otro lado de los Montes. Por otra parte, en determinados contextos, "territorium legionense" o "terra Legionis" sirve para designar el reino de León en sentido estricto o conjunto de tierras diferenciadas de Asturias y Galicia, pero también de Castilla.

Entendida la expresión «territorium legionense» como distrito, el primer problema que se nos plantea es dilucidar cuál era su delimitación. Al tratarse de una zona carente de nítidos límites naturales es difícil, aunque no imposible, establecer, siquiera sea aproximadamente, las tierras englobadas bajo este término. En líneas generales la demarcación abarcaba las tierras en torno a la ciudad de León regadas por los ríos Bernesga, Torío, Esla y Porma. Una mayor precisión será posible al abordar el estudio de otros distritos limítrofes, lo que también nos permitirá determinar si el «territorium legionense» sufrió con el transcurso del tiempo modificaciones en sus límites o si éstos se mantuvieron inalterables.

Más problemático resulta establecer el sentido exacto de la expresión «suburbium». Ciertamente algunos lugares aparecen ubicados indistintamente en el «suburbium» 0 en el «territorium legionense», pero tenemos serias dudas de que ambos términos

5 Así, por ejemplo, en 1071 se localizan unas villas "...in territorio inter Istola et Ceia..."; cfr. Colección Sahagún, II, ed. M. HERRERO DE LA FUENTE, León, 1988, doc. nº 707.

6 Es el caso de Sollanzo, entre el Esla y el Porma, que formó parte del «territorium legionense», pero que, en ocasiones, aparece como «territorium»; cfr. Colección Sahagún, III, ed. M. HERRERO DE LA FUENTE, León, 1988, doc. ํㅜㄱㅜ․ 
fueran equivalentes, y la sospecha de que «suburbium» hacía referencia a un ámbito más reducido, restringido a lugares muy próximos a la ciudad, en tanto que el concepto «territorium» era más amplio. En cualquier caso la utilización del término «suburbium» cesa a fines del siglo $X$.

\section{LAS PRIMERAS MENCIONES A UNA AUTORIDAD CONDAL EN EL «TERRITORIUM LEGIONENSE»}

Desconocemos el momento exacto en que surgió este distrito propiamente dicho, es decir, con un personaje al frente y con centro en la ciudad de León. Carecemos de cualquier noticia hasta mediados del siglo $X$, y para estas fechas se limitan a una mención a la celebración de un juicio en la urbe regia ante el conde don Velasco ${ }^{7}$; tal vez el personaje que se hallaba en aquel momento encargado del gobierno del «territorium legionense», pero no podemos olvidar que León erá la capital del reino, y don Velasco podía ser un miembro del «palatium». Sería más concluyente y precisa al respecto la noticia acerca de que en 977 Pelayo Domínguez era «...preside in Legionense ciuitatis...", si no fuera porque tenemos la completa seguridad de que el texto hay que datarlo en $1077^{8}$.

Carecemos de cualquier testimonio posterior hasta el segundo cuarto del siglo XI, excepción hecha de algunas menciones al gobierno en León de García Gómez entre 990 y $1007^{9}$. Pero ello no nos parece determinante para afirmar la existencia de un distrito consolidado, habida cuenta de que tal gobierno en León, así como en Tierra de Campos, por parte del jefe del poderoso linaje Banu-Gómez fue puramente coyuntural, y hay que encuadrarlo en los azarosos momentos que vivió el Reino de León en

7 En 8 de febrero de 952 Munio y Ermesinda venden una tierra a orillas del Esla, al lado de Castro de Ardón, que habían obtenido "... per iudicio in Legione de Lub ante comite domno Uelasco..."; cfr. J. RODRÍGUEZ, El monasterio de Ardón. Estudio histórico sobre los centros monásticos medievales de Cillanueva y Rozuela, León, 1964, doc. $n^{\circ}$ IX. Con anterioridad a estas fechas únicamente hemos hallado una mención a un «...Vermudus legionensis comes...»; cfr. C. SÁNCHEZ-ALBORNOZ, "El régimen provincial en la monarquía astur-leonesa", Cuadernos de Historia de España, 67-68, 1982, p. 37 nota 9 .

8 Un documento original de la catedral de León (cfr. Colección León, II, ed. E. SÁEZ-C. SÁEZ, León, 1990, doc. $n^{\circ} 450$ ), fechado por los editores en 977 , recoge el conflicto que tuvo lugar entre el monasterio de San Cosme y San Damián de Abellar y unos particulares acerca de unos pomares en Santa Colomba, a orillas del Torío, en territorio legionense; dicho pleito se sustanció ante Pelayo Domínguez, «...qvi erat preside in Legionense ciuitatis...». Obviamente el término «praeses» denota ya una afirmación de gobierno que no deja lugar a dudas y que no aparecía en el documento al que anteriormente nos hemos referido. Pero este documento corresponde al año 1077, fecha que aparece en la copia del mismo; cfr. Colección León, IV, ed. J.M. RUIZ ASENCIO, León, 1990, doc. 꾸 1204. No tenemos dudas de que ésta sea la datación correcta porque en torno a los años 1078-1086 Pelayo Domínguez fue merino en León. Por otra parte, examinado el original, se aprecia un pliegue en el pergamino donde estaría escrito «C».

9 Colección León, III, ed. J.M. RUIZ ASENCIO, León, 1991, doc. ํㅜ 534, 535, 666 y 667. 
tiempos de Almanzor, con cuya protección García Gómez logró expulsar de la sede regia a Vermudo $\mathrm{II}^{10}$.

Así pues - si exceptuamos las poco clarificadoras menciones a los"condes Vermudo y Velasco, y teniendo en cuenta las peculiares circunstancias que concurrieron en el gobierno en León de García Gómez- de cuanto acabamos de indicar creemos que se puede concluir que el distrito surgió tardíamente, debido seguramente a que era innecesario, por ser dicha urbe la sede regia y estar estas tierras bajo el control directo del monarca. Es preciso esperar a las postrimerías del reinado de Vermudo III; es entonces cuando se empiezan a consignar con cierta regularidad en los fondos de la catedral de León los nombres de los personajes que estuvieron al frente del distrito cuyo centro era la ciudad de León.

Al iniciarse el segundo cuarto del siglo XI es posible que gobernara esta demarcación el conde Muño Muñoz ${ }^{11}$, y unos años después, reinando Vermudo III, tenemos ya constancia cierta de que se hallaban al frente de la misma Fernando Flaínez y su hijo Flaíno Fernández, importantes magnates hacendados en la montaña leonesa ${ }^{12}$, quienes continuaron en el cargo al producirse la entronización de la dinastía navarra ${ }^{13}$.

10 Sobre García Gómez cfr. J.M. RUIZ ASENCIO, "Rebeliones leonesas contra Vermudo II», Archivos Leoneses, 45-46, 1969, pp. 215-235; J.M․a. FERNÁNDEZ DEL POZO, “Alfonso V, rey de León», en León y su Historia. Miscelánea Histórica, V, León, 1984, pp. 44 ss.; J. MONTENEGRO, Santa María de Piasca. Estudio de un territorio a través de un centro monástico (857-1252), Valladolid, 1993, pp. 183 ss.

11 Este personaje, hacendado en Trobajo y en la propia ciudad de León (ctr. Colección León, III, doc. $n^{\circ} 840$ y 867 ) pertenecía a la nobleza magnaticia; durante el reinado de Alfonso $V$ ostentó el cargo de mayordomo entre los años 1012-1013 y 1017-1019 (cfr. J.Mª. FERNÁNDEZ DEL POZO, "Alfonso $V$ ", doc. $\mathrm{n}^{\circ} 11,12,13,18,20,21$ y 25). Los indicios de que pudo gobernar el distrito se reducen a su aparición en la subscripción de un documento a continuación del rey y del obispo de León en 1026, y a que un año más tarde actuaba como «uigarium regis» confiscando las propiedades de Ratario, quien le entregó en oferción un majuelo en Valdefresno; cfr. Colección León, III, doc. ํํ 828 y 838 .

12 Sobre el linaje Flaínez cfr. P. MARTíNEZ SOPENA, "El conde Rodrigo de León y los suyos. Herencia y expectativa de poder entre los siglos X y XII", en Relacciones de poder, de producción y parentesco en la Edad Media y Moderna, R. PASTOR (comp.), Madrid, 1990, pp. 51-84.

13 Las únicas menciones expresas del gobierno de Fernando Flaínez se circunscriben a fechas comprendidas entre 1036 y 1038. C. ESTEPA, Estructura social de la ciudad de León (siglo XI-XIII), León, 1977 , p. 241, nota 205, cita un documento de 1036 en el que consta el personaje «mandante in Legione". Lo mismo ocurre con diversos textos de la catedral de León datados entre febrero y mayo de 1038; cfr. Colección León, IV, doc. $n^{0} 960,961,965$ y 966 . Pero hay indicios como para poder afirmar que su gobierno, compartido con su hijo, se inició tiempo atrás, con el reinado de Vermudo Ill. Así parece desprenderse de un documento de 1032 en el que se recoge el conflicto que tuvo lugar entre el obispo de León y un morador en la villa de Reliegos, y la intervención del conde Flaíno Fernández "...qui tenebat ipsa terra sub suas manos post mortem de domno Adefonso princeps..."; cfr. Colección León, IV, doc. $n^{\circ}$ 899. Fernando Flaínez y Flaíno Fernández se mantuvieron en el cargo cuando en 1034 el rey Sancho el Mayor estaba en León; cfr. Colección Sahagún, II, doc. no 439. Su gobierno debió de prolongarse durante buena parte del reinado de Fernando I. Así, por ejemplo, en 1045 se celebró un juicio por homicidio «... ad concilio in Legione ante comite Fredenando Flaginez et Flagino Fredenandez et Ciprianus episcopus...»; cfr. Colección León, IV, doc. $n^{\mathrm{O}} 1029$. Fernando Flaínez se 
Vemos, pues, cómo hasta bien entrado el siglo XI aparecen con una cierta discontinuidad una serie de personajes, de los cuales sólo de Fernando Flaínez, y para un breve periodo de tiempo, nos consta fehacientemente que gobernó el distrito, sin que se configure con nitidez la existencia de una demarcación con sede en León propiamente dicha, cuando en otros ámbitos próximos este proceso se había ya consolidado tiempo atrás. A este respecto cabría preguntarse cuál fue la función de Fafila Pérez, sobrino carnal de Fernando Flaínez ${ }^{14}$. Fafila Pérez, que jugó un importante papel durante el reinado de Vermudo III, de quien fue "pincerna", es decir, mayordomo ${ }^{15}$, aparece en la subscripción de un documento de junio de 1037, a continuación del rey Vermudo y del obispo de León, «Sub cuius comitatum Fafila Petriz hic in Legione...» ${ }^{16}$, lo que podría denotar que Fernando Flaínez gobernó no sóio con la colaboración de su hijo sino también de su sobrino; todo ello sin olvidar la intervención del obispo de León en algunas de las actividades que tenemos documentadas de Fernando Flaínez y Flaíno Fernández en el gobierno de León. Observamos en esta demarcación ciertas peculiaridades, derivadas sin duda del hecho de ser León la capital del reino y sede de un obispado. En este orden de ideas nos parecen muy expresivas las palabras de P. Martínez Sopena al referirse al gobierno sobre el distrito de diversos miembros del linaje Flaínez: «... ha mantenido (esta familia) cierto poder sobre la capital y su entorno desde los tiempos de Vermudo III...»17.

Tales peculiaridades, por lo que atañe a este ámbito territorial, no desaparecen en años sucesivos. Si exceptuamos dos menciones a Martín Flaínez, hijo de Flaíno Martíne $z^{18}$, e importante magnate de la corte de Alfonso $\mathrm{VI}$, que permiten sospechar que gobernó el distrito legionense, para el largo periodo comprendido entre mediados del siglo XI y la llegada al trono de doña Urraca carecemos de testimonios acerca de quién ostentaba tal dignidad ${ }^{19}$. Esta ausencia de menciones se halla, desde nuestro

mantendría en el gobierno de León hasta 1049, pues de este año data la última aparición del magnate en la corte de Fernando I, en la que hasta entonces figuró regularmente; cfr. Colección diplomática de Fernando l (1037-1065), ed. P. BLANCO LOZANO, León, 1987, doc. nำ 8, 16, 20, 28, 29, 31, 34 y 40.

14 C. ESTEPA, Estructura social, p. 243.

15 Como «pincerna in palacio» aparece en un documento original de 1030 y como «maiordomus", "egonomus" o "merinus" en 1032, 1035 y 1036; cfr. "Colección diplomática de Vermudo III, rey de León", ed. L. NÚÑEZ CONTRERAS, Historia. Instituciones, Documentos, 4,1977 , doc. no 4, 8, 13, 18 y 19.

16 Colección León, IV, doc. ํำ 955.

17 P. MARTÍNEZ SOPENA, «El conde Rodrigo», p. 53.

18 P. MARTÍNEZ SOPENA, «El conde Rodrigo», pp. 63-64 y nota 33.

19 De un texto de 31 de marzo de 1091 - Alfonso $\mathrm{VI}$ se dirige al obispo de León y a «...uobis honorabili comiti Martino Flainiz, seu etiam omnibus...conmorantibus in tota terra de Legione...»- parece deducirse tal posibilidad, así como de la alusión algo posterior (data de 17 de díciembre de 1106) a un "Comes domnus Martinus Legionense...»; cfr. Colección León, IV, doc. n 1256 y 1321. Sí nos consta, sin lugar a dudas, que Martín Flaínez gobernó otros distritos, como Simancas (1084-1092), Aguilar (1096-1108), Peñamián (1105), o Ceión (1104); cfr. Colección Sahagún, III, doc. no 815, 843, 856, 863, $868,872,893,921,934,994,1020,1022,1109,1112,1159$ y 1165 y Colección León, IV, doc. $\mathrm{n}$ ำ 1318. Debió de morir hacia 1108 , pero no en la rota de Uclés, como pretende B.F. REILLY, El reino 
punto de vista, en relación con los cambio llevados a cabo por Fernando I en la organización territorial de sus reinos; reorganización que incidiría en un distrito poco consolidado, como era el de León, en mayor medida que en otros, en los que no resultaría fácil desmontar las viejas estructuras. Nos estamos refiriendo en concreto a la aparición de los merinos del rey como oficiales permanentes en un determinado ámbito territorial ${ }^{20}$, lo que en el caso del distrito de León debió de significar el oscurecimiento y tal vez desaparición, siquiera sea temporal, de la figura del conde (al que desde los inicios del reinado de Fernando I se empieza a denominar "mandante» 0 «imperante» al margen de que disfrute de la dignidad condal). Pues frente a la escasez de referencias a una autoridad condal, en cambio, empiezan a ser relativamente frecuentes las menciones al personaje que ostentaba el cargo de merino en el distrito.

\section{LOS MERINOS DEL REY}

Casi coincidiendo con la desaparición de la documentación de Fernando Flaínez, los textos de la catedral de León empiezan a consignar con una cierta insistencia la presencia y actuaciones de merinos del rey en León. Un documento original datado el 4 de marzo de 1052 nos presenta a un merino ejerciendo funciones como tal en esta demarcación; con motivo de un pleito sobre la posesión de la villa de Llanos entre el obispo de León y el abad de San Pelayo, que se sustanció ante los reyes y los magnates de Palacio, Fernando Salvadórez, «...qui est merino in Legione...», interviene, en compañía de otros personajes, en la delimitación de la villa en litigio ${ }^{21}$. No es la única mención a este personaje, de quien en 28 de febrero de 1055 se indica, en la subscripción de un documento, que era "...merino rex in Legione», inmediatamente después del obispo de León ${ }^{22}$.

Con los datos que acabamos de indicar creemos que es posible afirmar que nos hallemos en presencia de un merino del rey con atribuciones sobre un ámbito territo-

de León y Castilla bajo el rey Alfonso VI (1065-1109), trad. por G. Otálora Otálora, Toledo, 1989, pp. 378 ss., pues en noviembre de dicho año todavía figura en Aguilar; cfr. Colección Sahagún, III, doc. $\mathrm{n}^{\circ}$ 1165. Algo similar podemos decir con respecto a la presencia en el gobierno de León, ya durante el reinado de doña Urraca, de Froila Díaz, otro miembro del linaje Flaínez (cfr. P. MARTíNEZ SOPENA, «El conde Rodrigo», p. 67). En julio de 1109 aparece Froila Díaz como «legionemsium comes" y a fines de 1110 como "count in terra de legione et in gralare»; cfr. B.F. REILLY, The Kingdom of León-Castilla under Queen Urraca, 1109-1126, Princeton, 1982, pp. 292-293. Este autor considera que el título de «legionemsium comes» es puramente honorífico y sitúa su gobierno en León en 1110 en relación con las circunstancias de la ruptura entre Urraca y Alfonso de Aragón.

20 Sobre la aparición de estos oficiales cfr. J. MONTENEGRO, «La administración territorial», pp. 335-336.

21 Colección León, IV, doc. $\mathrm{n}^{\mathrm{Q}} 1085$.

22 Colección León, IV, doc. $\mathrm{n}^{\mathrm{Q}}$ 1096. Fernando Salvadórez confirma también como «preposito regis" y como «uicario» en sendos documentos de 1052; cfr, en este mismo volumen doc. no 1082 y 1084. No hemos hallado más noticias sobre Fernando Salvadórez, quien en ningún momento figura en la corte de Fernando I. 
rial definido, el «territorium legionense»; dicho oficial sería el único instrumento de que se valía el rey en aquellos momentos para controlar el distrito. Desde luego, estos testimonios refuerzan nuestra idea, ya manifestada anteriormente ${ }^{23}$, en el sentido de que, a raíz de la entronización de la dinastía navarra, se empezó a potenciar en los reinos occidentales la figura de merinos del rey, que empiezan a actuar en algunos distritos al margen o incluso en lugar de los antiguos condes, constituyendo el embrión de una nueva fórmula de organización territorial, a la que brindará un notable impulso Alfonso VI. A este respecto hemos de tener en cuenta que en 1061 Fernando I y doña Sancha donan una heredad a San Millán de la Cogolla, solucionando las irregularidades que se habian producido en la transmisión de la misma, previa intervención del merino del rey, «Quia merino nostro Flagino Aurioliz inquisiuit et ita debet esse». Otras menciones a merinos del rey se detectan en 1064; uno de ellos, Oveco Gelmírez, actuaba, al parecer, en la tierra de Lemos y Sarriá como merino mayor, y aproximadamente por las mismas fechas Suero Titóniz y Velasco Fernández eran vicarios de los reyes en territorio de Limia $^{24}$. Ciertamente en estos casos - y en concreto por lo que atañe a la intervención del merino real en la donación a San Millán de la Cogolla - se puede pensar que tales merinos se limitaron a llevar a cabo una tarea específica en un momento determinado, pero en otros casos nos parece evidente que se trata de agentes estables en un ámbito territorial perfectamente definido. Así, por ejemplo, tenemos constancia de la existencia de un merino del rey en Lampreana en $1042^{25}$. Todavía más expresivo es un diploma de 1063 en el que aparecen entre los testigos "Gemeno Belazquiz maiorinus opido Lunae. Pelagis Cidiz maiorinus totius Vergido ${ }^{26}$. Por su parte, B.F. Reilly recoge testimonios de lo que él denomina «merinos del fisco real» actuantes en el territorio de Portugal durante el reinado de Fernando I, a partir de $1045^{27}$. Efectivamente, en 10 de junio de 1065, a petición del obispo de Santiago, Fernando I puso coto a las intromisiones en las propiedades de la Iglesia de Santiago «in terra portugalensi» por parte de «...sui egonomi de Portugali, nominati Didacus Tructesindici, Sisnandus lohannes et Tedon Telici...». De este último se indica en 13 de junio de ese mismo año que, junto con Diego Arveréndiz y Fernando Juánez, eran «...nobilis et magnae dignitates viros scilicet gubernans terram portugallense vicarios suos...». Tedón Téllez aparece por estas mismas fechas como confirmante en otro documento referente a las tierras de Portugal28.

23 Cfr. nota 20.

24 Fernando I, ed. P. BLANCO LOZANO, doc. № 56, 119 y 121; O Tombo de Celanova: estudio introductorio, edición e indices (ss. IX·XII), ed. J.M. ANDRADE CERNADAS coa colaboración de M. DÍAZ TIE e F.J. PÉREZ RODRÍGUEZ, I, Santiago de Compostela, 1995, doc. $\mathrm{n}^{\circ} 260$.

25 En la subscripción de la donación de una villa en el territorio de Lampreana aparece «Uita Didaz maiorinus regis in Lampriana conf.»; cfr. Fernando I, ed. P. BLANCO LOZANO, doc. n 19.

26 Fernando l, ed. P. BLANCO LOZANO, doc. no 67.

27 B.F. REILLY, Alfonso VI, p. 260 y nota 13.

28 Fernando l, ed. P. BLANCO LOZANO, doc. $n^{\circ} 73,74$ y 75 . J. Mattoso considera que estos tres personajes -Diego Tructesíndiz, Sisnando Juánez y Tedón Télez- administraron el condado portucalense al menos entre 1063 y 1065; cfr. J. MATTOSO, A Nobreza Medieval Portuguesa. A Famillia e o Poder, 4 ed. revista, Lisboa, 1994, p. 269 y nota 67. 
Tenemos que insistir una vez más en la necesidad ineludible de llevar a cabo un análisis pormenorizado de las distintas demarcaciones antes de ofrecer resultados concluyentes sobre estos y otros aspectos relacionados con la organización territorial de los reinos occidentales, pero parece claro que los indicios apuntan en la dirección indicada. El «territorium legionense» sería uno de los primeros distritos donde se aplicó la nueva fórmula por las razones ya manifestadas.

Desde luego, desde el inicio del reinado de Alfonso VI se aprecia con nitidez la existencia de merindades de límites territoriales bien definidos y con unos oficiales - los merinos del rey- al frente de las mismas con carácter estable, en lo que se adivina como la prosecución de una tarea emprendida por su padre. Es el caso de merindades como Saldaña o Carrión, entre otras, que, en cuanto a su denominación, características y, en buena medida, en cuanto a sus límites geográficos, responden a la división en merindades de la Castilla al norte del Duero, perfectamente configurada un siglo después. Ahora bien es evidente que este proceso, iniciado por Fernando I y consolidado por su hijo, afectó también al reino de León. Ya nos hemos referido más arriba a la existencia de un merino del rey en el Bierzo en 1063; a fines de 1071 este cargo todavía lo ostentaba Pelayo Cídiz ${ }^{29}$. Tenemos fundadas sospechas de que unos años antes fue merino del rey en Astorga Juan Adúlfiz ${ }^{30}$, y constancia documental de que por lo menos en fechas comprendidas entre 22 de marzo de 1090 y 22 de noviembre de 1093 Ero Eriz desempeñaba estas mismas funciones ${ }^{31}$, y en 1104 Ero Gutiérrez $^{32}$, seguramente el mismo personaje que también por estos años era merino del rey en Zamora ${ }^{33}$. Los límites geográficos de las merindades de El Bierzo, Astorga, y Zamora con Campo de Toro serían coincidentes con los de los distritos del mismo nombre, configurados como tales desde mucho tiempo atrás.

En concreto, y por lo que atañe al ámbito territorial objeto de nuestro estudio, es claro que durante el reinado de Alfonso $\mathrm{VI}$ se consolidó una merindad de León. Si durante el reinado de Fernando I las alusiones a un merino del rey en León son esporádicas, las menciones a estos oficiales, sobre todo a raíz de la reunificación de los

29 B.F. REILLY, Alfonso VI, p. 79 y nota 58.

30 En 1068 Juan Adúlfiz aparece confirmando como «...uicario de ille rex...» en un documento original relativo a la entrega, en concepto de homicidio, al abad don Martín de una heredad en Villar de Azmún, en territorio de Astorga. Existe otro documento, recogido en el Tumbo, con la misma fecha y el mismo contenido, pero en el que, además de variar notablemente las personas implicadas, se hace constar que dicho homicidio se pagó “...pro persolutione de maiorino de rege, lohanne Adulfiz...»; cfr. Colección León, IV, doc. n² 1157 y 1158.

31 Colección Sahagún, III, doc. no 860 y 914 . Por estos años Ero Eriz fue también merino en Toro; cfr. en este mismo volumen doc. $\mathrm{n}^{\circ} 891$ y Colección León, IV, doc. $\mathrm{n}^{\circ} 1277$.

32 Colección Sahagún, III, doc. $n^{0} 1103$.

33 Colección Sahagún, III, doc. ํํ 1107 y 1113. Y seguramente en Toro, pues el negocio jurídico de uno de estos textos afecta a Villacete (actual Belver de los Montes), lugar que los documentos de Sahagún sitúan en Campo de Toro. Ambos territorios, Zamora y Campo de Toro, aparecen vinculados, hasta el punto de configurar un único distrito, en fechas anteriores; cfr. Colección Sahagún, II, doc. $n^{2} 400,611$ y 619 . 
reinos, se hacen constantes hasta el punto de permitirnos observar la permanencia en el cargo de un mismo personaje durante un largo periodo de tiempo.

Inicia la serie de merinos del rey en León Domingo Pérez, a quien tenemos documentado como tal en los últimos meses del año $1073^{34}$. Entre agosto de 1075 y marzo de 1077 tal vez desempeñó el cargo Tello Gutiérrez ${ }^{35}$, a quien podemos identificar con el conocido miembro del linaje Alfonso que fue también mayordomo del rey ${ }^{36}$. En 1077 aparece Pelayo Domínguez; éste ejerció como merino posiblemente hasta 1088 y con toda seguridad hasta septiembre de $1086^{37}$. Entre marzo y octubre del año 1090 nos consta que fue merino de León Gómez Donélliz ${ }^{38}$, y entre marzo de 1092 y abril de 1097 Ordoño Peláez ${ }^{39}$. El último merino del rey en León durante el reinado de Alfonso VI fue Miguel Alfonso ${ }^{40}$, con seguridad el mismo personaje que en 14 de abril de 1097 era merino de Astorga $^{41}$. Las menciones a su actividad como merino de León se pro-

34 Colección León, IV, doc. no 1190 y 1191. Según C. ESTEPA, Estructura social, p. 447, era un personaje de la corte de Alfonso $\mathrm{VI}$, pues en 1071 confirma una donación del monarca a su hermana Urraca. Tal vez, pero no muy destacado, pues no ha dejado rastro posterior de sus actividades y presencia en la corte.

35 Colección León, IV, doc. $\mathrm{n}^{\mathrm{Q}} 1195$ y 1202.

36 A Tello Gutiérrez lo tenemos registrado como mayordomo del rey en noviembre de 1073; cfr. Colección León, IV, doc. n 1190. Sobre el tinaje Alfonso, cfr. P. MARTÍNEZ SOPENA, «Parentesco y poder en León durante el siglo XI. La «casata» de Alfonso Díaz», Studia Historica. Historia Medieval, V, 1987, pp. 37-87 y J. MONTENEGRO, Santa María de Piasca, pp. 71 ss.

37 Documentos de la catedral de León testimonian a Pelayo Domínguez como merino en León entre 7 de mayo de 1077 y 20 de septiembre de 1086; cfr. Colección León, IV, doc. $\mathrm{n}^{\mathrm{Q}}$ 1204, 1211, $1213,1217,1220,1221,1228,1239$ y 1240, y Colección Sahagún, III, doc. nº 782 y 826 . De un texto de Sahagún (cfr. en este mismo volumen doc. no 840 ) se podría deducir que en 1088 Pelayo Domínguez todavía era merino de León. En 1086 Pelayo Domínguez era también merino de Toledo; cfr. Colección Sahagún, III, doc. $\mathrm{n}^{\circ}$ 826. Presumiblemente Alfonso VI le retribuiría con este nombramiento a raíz de su conquista.

38 Sendos documentos de la catedral de León y del monasterio de Sahagún así lo atestiguan; cfr. Colección León, IV, doc. ํㅜ 1251 y Colección Sahagún, III, doc. ํo 860.

39 Colección León, IV doc. no 1266, 1274, 1277, 1282, 1289 y 1293, y Colección Sahagún, III, doc. $n^{\circ} 914,918,922,934,959,994$ y 996. Un documento de Sahagún (cfr. Colección Sahagún, III, doc. $\mathrm{n}^{\circ}$ 830) permitiría retrotraer a 1087 el inicio de Ordoño Peláez como merino de León. Pero, puesto que tenemos dos testimonios coincidentes, un documento de la catedral de León y otro del monasterio de Sahagún, originales ambos, sobre Gómez Donélliz como merino de León en 1090, y como seguramente en 1088 todavía lo era Pelayo Domínguez, parece forzoso concluir que el documento de Sahagún, no 830, una copia, tiene un error de datación. Ordoño Peláez en 1095 era también merino en Cea; cfr. Colección Sahagún, III, doc. nº 934 y 959 . En diciembre de 1096 aparece un merino distinto en Cea; cfr. en este mismo volumen doc. $n^{\circ} 994$. Seguramente estas tierras del Cea, que habían constituido una demarcación desde mediados del siglo $X$, solamente se integraron en la merindad de Saldaña a raíz de la división de los reinos entre los hijos de Alfonso VII, pues todavía en 1146 Cea constituía una merindad diferenciada de la de Saldaña; cfr. Colección Sahagún, IV, doc. no 1290.

40 La primera mención en documentos de la catedral de León data de 17 de enero de 1098; cfr. Colección León, IV, doc. n 1295.

41 Colección León, IV, doc. $n^{0}$ 1293. En 17 de enero de 1098 tenemos constancia de un merino distinto en Astorga; cfr, en este mismo volumen, doc. $n^{\circ} 1295$. 
longan hasta $1107^{42}$, pero muy probablemente se mantuvo en el cargo hasta la muerte de Alfonso VI, pues la primera noticia de un merino distinto en León data de 1 de febrero de $1110^{43}$. Llegamos así al reinado de doña Urraca con un claro predominio de la figura del merino, que oscurece completamente al conde o tenente del distrito, virtualmente inexistente durante este periodo.

\section{MERINOS Y TENENTES EN EL «TERRITORIUM LEGIONENSE»}

El reinado de doña Urraca se inaugura con una novedad: la aparición de un tenente de las torres de León. Ejercieron sucesivamente este cargo Pelayo Muñoz, Pedro Díaz, Jimeno López y Pedro Braulez ${ }^{44}$. Y nos parece digno de reseñar que dos de estos tenentes -Pedro Díaz y Jimeno López- fueron también merinos de la reina en León. Pedro Díaz ostentaba tal cargo en junio de 1111 y en agosto de 1116, y Jimeno López en diciembre de $1119^{45}$, unos meses antes de su aparición como tenente de las torres. Este personaje fue también mayordomo de la reina, así consta en los dos textos que consignan su tenencia de las torres. No fueron éstos los únicos merinos en León durante el reinado de la hija de Alfonso VI. En septiembre de 1109 ostentaba tal cargo Pedro Domínguez; en 1114 Domingo Rodríguez, y otros aparecen en los últimos años del reinado ${ }^{46}$. Merinos y tenentes de las torres actúan simultáneamente en el distrito legionense ${ }^{47}$, y es lógico pensar que, al menos en principio, unos y otros tenían sus

42 Colección León, IV, doc. n 1295, 1296, 1299, 1304, 1305, 1316, 1319 y 1321, y Colección Sahagún, III, doc. no 1057, 1103, 1111, 1125 y 1158. De los dos últimos documentos citados se desprende que Miguel Alfonso fue también merino de Cea y Castro Froila (en la actualidad Castrofruela es un despoblado entre Saelices de Mayorga y Villalba de la Loma).

43 Colección León, V, doc. nำ1332.

44 A Pelayo Muñoz lo tenemos documentado como «tenente arces Legionis" en 18 de mayo de 1110 (cfr. Colección León, V, doc. n 1334); a Pedro Díaz en 7 de junio de 1114 y entre 1 de abril de 1117 y 18 de marzo de 1118 (cfr. en este mismo volumen doc. n 1349, 1357 y 1361); a Jimeno López a mediados de 1120 (cfr. en este mismo volumen, doc. $n^{\circ} 1367$ y 1368); a Pedro Braulez entre 1 de enero de 1123 y 30 de junio de 1124 (cfr. en este mismo volumen, doc. $n^{\circ} 1379$ y Colección Sahagún, IV, doc. $n$ - 1213). Pedro Braulez con Alfonso VII no recuperó la tenencia de las torres, aunque fue un personaje importante en su corte; cfr. M. RECUERO ASTRAY, "El reino de León durante la primera mitad del siglo XII", en El reino de León en la Alta Edad Media, IV, La monarquía (1109-1230), León, 1993, p. 42. Por lo que respecta a la presencia en León de Pedro Cathamosca, vicario de Alfonso el Batallador, y tal vez tenente de las torres en 3 de junio de 1112 (cfr. Coleción León, V, doc. no 1337), debió de ser puramente coyuntural y consecuencia de las vicisitudes derivadas del enfrentamiento entre la reina Urraca y su esposo.

45 Cfr. Documentos del monasterio de Santa María de Trianos (siglos XII-XIII), ed. G. CASTÁN LANASPA y J. CASTÁN LANASPA, Salamanca, 1992, doc. $\mathrm{n}^{\circ}$ 1, y Colección León, V, doc. $\mathrm{n}^{\circ} 1355$ y 1365.

46 Colección León, $V$, doc. $n^{0} 1328,1332,1333,1349,1372$ y 1379.

47 Poseemos algunos testimonios de la actuación simultánea de merinos y tenentes. Así, por ejemplo, en 7 de junio de 1114: «Domingo Rodriquiz maiorino maior in Legione... Petro Diaz tenente illas torres de Legione", y en 30 de junio de 1124: «Petro Braolez tenente illas turres. Nunno Gonzaluez maiorino in Legione»; cfr. Colección León, $\mathrm{V}$, doc. $\mathrm{n}^{\circ} 1349$ y 1379. 
competencias perfectamente delimitadas. Una situación muy similar detectamos durante el reinado de su hijo y sucesor.

Entre los años 1141 y 1147 del reinado del Emperador creemos apreciar una situación de crisis en la tenencia de las torres; a la luz de la documentación conservada, en este breve espacio de tiempo se sucedieron en el cargo: Pedro Peláez, que compatibilizó este cargo con el de merino hacia 1141, al igual que Pedro Manga en 1142, Albertino en 1143 y Anaya Rodríguez en fechas comprendidas entre 1145 y $1147^{48}$. Habida cuenta de que de dos de estos personajes - Pedro Manga y Anaya Rodríguez- tenemos noticias de sus actividades como merinos del rey en León en torno a estas fechas ${ }^{49}$, y de que no hay constancia documental de ningún tenente de las torres que no sea al mismo tiempo merino, parece razonable pensar que durante este periodo de tiempo los merinos del rey extendieron el ámbito de sus competencias a las propias de los tenentes de las torres de León. Es una situación anómala, sin duda, pero que no afectó en exclusiva a esta demarcación, pues aproximadamente por las mismas fechas algo similar ocurrió en los distritos de Saldaña y Carrión ${ }^{50}$.

Ahora bien, si prescindimos de estos años, observamos que durante el reinado de Alfonso VII ostentaron la tenencia de las torres de León el conde Rodrigo Martínez y Poncio de Minerva. Aquél se mantuvo en el cargo desde la llegada al trono de Alfonso VII hasta 1138 , fecha de su muerte en el asedio de Coria ${ }^{51}$. Y, después de un breve paréntesis - representado por Rodrigo Vermúdez, que consta como tenente de las torres de mano de la reina doña Berenguela en $1140^{52}$, ostentó el cargo Poncio de

481140 [0 1141]. Diciembre 29: «Villico regis Pe[trus P]elaiz tenente turres de Legione»; 1142. Enero 2: Pedro Manga «uillicante et turres tenente»; 1143. Junio 26: don Albertino «turres Legionis tenente, atque ibi uillicante»; 1145. Marzo 30: Anaya Rodriguez «turres legionis tenente, et in eadem uilla uillicante»; 1147: “maiorino in Legione, Anaia Rodriguez, ipso tenente turres Legionis»; cfr. Colección León, V, doc. no 1430, 1435, 1441 y 1449, y M.L. GARCÍA CALLES, Doña Sancha, hermana del emperador, León-Barcelona, 1972, p. 145.

49 Pedro Manga aparece como merino en 1141, 1143 y 1149; cfr. A.H.N. Eslonza, carp. 962 , $n^{\circ}$ 15, y Colección León, V, doc. no 1442 y 1459. Anaya Rodríguez en 1146 y 1147; cfr. Colección León, V, doc. no 1451, y Colección Sahagún, IV, doc. nº 1287, 1290 y 1294.

50 Cfr. J. MONTENEGRO, «La administración territorial», pp. 341-344.

51 Colección León, V, doc. $n^{2}$ 1383, 1387, 1388, 1389, 1390, 1392, 1393, 1397, 1401, 1410, 1417 y 1422, y Colección Sahagún, IV, doc. $\mathrm{n}^{\mathrm{0}}$ 1226, 1230, 1233, 1236, 1242, 1243, 1245, 1250, 1255 , 1264. Ciertamente un documento de 1131 (cfr. Colección León, V, doc. $n^{\circ}$ 1399) indica que la tenencia de las torres estaba en manos de Martín Nepociániz, a quien podemos identificar con el personaje que en 1132 y en torno a los años 1150-1153 fue merino del rey en León. Martín Nepociániz desem. peñaría la funciones de tenente en nombre de Rodrigo Martínez. Este último por estos mismos años fue también tenente de Aguilar, Zamora, Melgar, Astorga..., así como alférez del Emperador; cfr. Colección Sahagún, IV, doc. $n^{0}$ 1225, 1236, 1244, 1250 y 1264; Trianos, ed. G. CASTÁN LANASPA y J. CASTÁN LANASPA, doc. $n ³$; M. RECUERO ASTRAY, «Donaciones de Alfonso VIl a sus fieles y servidores", En la España Medieval, 9, Estudios en memoria del Prof. D. Claudio Sánchez-Albornoz, Madrid, 1986, p. 903; P. MARTÍNEZ SOPENA, «El conde Rodrigo», pp. 71-72.

52 Cfr. Colección León, V, doc. n 1429 y Colección Sahagún, IV, doc. ํำ1271. Rodrigo Vermúdez fue mayordomo del Emperador; cfr. M. RECUERO ASTRAY, «El reino de León», p. 53. 
Minerva desde 1148 hasta 1168 , momento en que abandonó la corte de Fernando $\|^{53}$. Tanto Rodrigo Martínez como Poncio de Minerva fueron relevantes magnates, en especial Rodrigo Martínez, perteneciente a una estirpe de la primera nobleza del reino. Era miembro del linaje Flaínez — hijo del conde Martín Flaínez ${ }^{54}$-, muy vinculado al gobierno de León desde los tiempos de Vermudo III. Rodrigo Martínez recibió la dignidad condal en 1127, participó activamente, siempre fiel al Emperador, en el sometimiento de varias rebeliones nobiliarias y fue hasta su muerte el primer magnate de su corte ${ }^{55}$. Poncio de Minerva llegó a León acompañando a doña Berenguela, estuvo junto al Emperador en la empresa de Almería, fue su alférez desde 1140 y recibió numerosas donaciones de Alfonso VII; fue uno de los nobles, por parte leonesa, que garantizó el tratado de Sahagún de $1158^{56}$; entroncó con el linaje Flaínez, pues era yerno de Ramiro Froilaz, hijo a su vez de Froila Díaz ${ }^{57}$. Ambos -Rodrigo Martínez y Poncio de Minerva- ejercieron el cargo sin interrupción y durante un dilatado periodo de tiempo.

No ocurrió así con los merinos del rey; poseemos una larga lista de tales oficiales que ejercieron su actividad durante breves periodos de tiempo - es el caso de Isidoro Nepociániz, documentado como merino del rey en León en diversos textos de 1129, de Juan Peláez, que ejerció el cargo en 1140, de Diego Muñoz en 1148, o de Rodrigo González en 1153-115458 - y a veces de manera discontinua —es el caso de Albertino

53 Colección León, V, doc. no 1457, 1458, 1459, 1460, 1461, 1473, 1477, 1480, 1482, 1486, 1488, $1489,1490,1491,1493,1494,1497,1498,1500,1503,1504,1505,1508,1514,1516,1517,1521$, $1528,1537,1538$, y 1539, y Colección Sahagún, IV, doc. nº 1304, 1308, 1335 y 1339. Fue también tenente de Cea, Valladolid, Mayorga, Melgar...; cfr. Colección Sahagún, IV, doc. no 1280, 1288, 1290, $1302,1310,1311,1322,1323,1326,1335,1340,1341,1342,1355$ y 1356; Trianos, G. CASTÁN LANASPA y J. CASTÁN LANASPA, doc. $\mathrm{n}^{\circ} 6$ y 8 . Sobre las vicisitudes del personaje después de abandonar la corte de Fernando II, cfr. J. GONZÁLEZ, El reino de Castilla en la época de Alfonso VIII, I, Madrid, 1960, p. 178.

54 Sobre la filiación del conde Rodrigo Martínez, cfr. P. MARTÍNEZ SOPENA, “El conde Rodrigo", p. 52 , nota 2 .

55 M. RECUERO ASTRAY, Alfonso VII, Emperador. El imperio hispánico en el siglo XII, León, 1979 , pp. 103 y 115; «Donaciones de Alfonso VII», pp. 903-904; “El reino de León», pp. 51-55, 66, 6869, 73-74.

56 J. GONZÁLEZ, Regesta de Fernando II, Madrid, 1943, p. 32; M. RECUERO ASTRAY, Alfonso VII, p. 145; “Donaciones de Alfonso VIl», pp. 900 y 903-904; S. BARTON, "Two Catalan magnates in the courts of the kings of León-Castile: the carreers of Ponce de Cabrera and Ponce de Minerva re-examined", Journal of Medieval History, 18, number 3, Special Issue: Aspects of Medieval Spain 711-1492, 1992, pp. 233-266.

57 P. MARTÍNEZ SOPENA, «El conde Rodrigo», p. 80.

58 Colección León, $V$, doc. n⿳⺈ 1387, 1388, 1389, 1390, 1429, 1430, 1457, 1482, 1483 y 1484; Colección Sahagún, IV, doc. ํำ1236 y 1269; A. RODRÍGUEZ GONZÁLEZ, «El Tumbo del monasterio de San Martín de Castañeda», Archivos Leoneses, 39-40, 1966, doc. ํㅜ 27. Más estabilidad en el cargo tuvieron Fernando Gutiérrez (1132-1136), Anaya Rodríguez (1145-1147) y Pedro Balzan (1155-1158); cfr. Colección León, V, doc. nº 1404, 1406, 1407,1408, 1409, 1410, 1413, 1415, 1416, 1417, 1449, 1450, 1451, 1486, 1488, 1489, 1490, 1491, 1493, 1494, 1497, 1498, 1500, 1503 y 1505; Colección Sahagún, IV, doc. no 1253, 1256, 1257, 1258, 1287, 1290, 1294, 1320 y 1324; J. GONZÁLEZ, Fernando II, p. 20. 
(1129-1132, 1138, 1143-1144), de Martín Nepociániz (1132, 1150-1153) o de Pedro Manga (1141-1143, 1149) ${ }^{59}$. Por otra parte, frente a la contrastada relevancia familiar, y sobre todo personal, de los tenentes de las torres, estimamos que podemos encuadrar a los merinos en el grupo de personas pertenecientes a familias con notoriedad a nivel comarcal o local. Así, Isidoro Nepociániz, al igual que su hermano Martín Nepociániz, figura en un documento de 1131 entre los "de Legionensis nobilibus" 60 ; Albertino fue un franco afincado en la ciudad y padre del obispo Juan Albertino ${ }^{61}$. Una condición similar tendrían los otros personajes que ostentaron el cargo de merinos en estos años.

Constituyen una excepción Anaya Rodríguez, Pedro Balzan, Diego Muñoz y Fernando Gutiérrez. Anaya Rodríguez fue un destacado magnate de la corte de Alfonso VII, al igual que Diego Muñoz y Pedro Balzan ${ }^{62}$. Por lo que atañe a Fernando Gutiérrez, tal vez haya que identificarlo con el hijo de Gutier Fernández, cabeza del linaje de los Castro, quien ostentó la mayordomía regia en fechas anteriores a la aparición como mayordomo del Emperador de Diego $\mathrm{Muñoz}^{63}$, pues detectamos una cierta vinculación entre el ejercicio de los cargos de mayordomo y merino. $Y$ no nos parece casual que sean precisamente estos merinos los que controlaron simultáneamente varias merindades. Anaya Rodríguez fue merino de León, Saldaña, Cea y Carrión, lo que explica que aparezca en 1147 como «merino maior imperatoris» ${ }^{64}$. Pedro Balzan fue merino en León, Coyanza y Luna ${ }^{65}$. Diego Muñoz fue merino del Emperador no sólo en León, sino también en Saldaña, Carrión y Cea ${ }^{66}$. Y Fernando Gutiérrez en León,

59 Colección León, V, doc. no 1392, 1393, 1394, 1397, 1399, 1401, 1402, 1435, 1440, 1441, 1442, 1446, 1459 y 1460; Colección Sahagún, IV, doc. n 1308, 1312 y 1314; A.H.N. Eslonza, carp. 962 , $\mathrm{n} \times 15$.

60 Documento del archivo de San Isidoro de León citado por C. ESTEPA, Estructura social, p. 286, nota 462. Ambos hermanos confirman documentos reales; cfr. M. RECUERO ASTRAY, «EI reino de León", p. 53, nota 150.

61 C. ESTEPA, Estructura social, pp. 181-182. Albertino esporádicamente confirma en documentos reales; cfr. M. RECUERO ASTRAY, «El reino de León», p. 147.

62 Anaya Rodríguez figura en diplomas del Emperador; cfr., entre otros, Colección Sahagún, IV, doc. n 1269, y Trianos, ed. G. CASTÁN LANASPA y J. CASTÁN LANASPA, doc. n 7. Diego Muñoz, hijo de Muño Díaz, el gran merino de Saldaña y Carrión durante el reinado de Alfonso Vl, fue mayordomo de Alfonso VII en torno a 1138-1144 y jugó un importante papel en los años centrales del siglo XII en Saldaña y Carrión; cfr. J. MONTENEGRO, «La administración territorial», pp. 341-344. Pedro Balzan fue uno de los "fideles vasalli» de Fernando Il confirmantes en el tratado de Sahagún de 1158 y su mayordomo en 1162; cfr. J. GONZÁLEZ, Fernando II, pp. 184 y 242.

63 Sobre Gutier Fernández, cfr. M. RECUERO ASTRAY, Alfonso VII, pp. 145-147; «Donaciones de Alfonso VIl», p. 904. En un diploma original, fechado en 1135, aparece Fernando Gutiérrez «...uillicus imperatoris...» a continuación del mayordomo, Gutier Fernández, y precediendo al alférez; cfr. Colec ción León, $\mathrm{V}$, doc. $\mathrm{n}^{\mathrm{0}} 1412$

64 Colección León, V, doc. nํ 1450; Colección Sahagún, IV, doc. o 1290 y 1293.

65 Documento citado por C. ESTEPA, Estructura social, p. 297, notas 556 y 557.

66 J. MONTENEGRO, “La administración territorial», pp. 341-344. 
Luna, Gordon, Coyanza y Asturias ${ }^{67}$. Pero, en cualquier caso, ninguno de estos personajes tuvo la notoriedad de Rodrigo Martínez o de Poncio de Minerva. Ello a pesar de que durante el reinado del Emperador los merinos desempeñaron un importante papel; buena prueba de ello es su asidua aparición en la corte ${ }^{68}$.

Frente a la situación que apreciamos hasta el momento de la muerte de Alfonso VII, caracterizada por una cierta notoriedad de los merinos, durante el reinado de Fernando II de León detectamos la desaparición de estos oficiales, por lo menos por lo que atañe al distrito objeto de nuestro estudio. Unos años después de la muerte del Emperador deja de figurar Pedro Balzan como merino del rey en León ${ }^{69}$. A partir de este momento los documentos de la catedral de León consignan la existencia de merinos en número variable, ninguno de los cuales aparece como merino del rey ${ }^{70}$. La aparición simultánea de varios merinos e incluso la onomástica personal de los mismos -Pedro Octava, Pedro Crespo, Isidoro Miliani, etc.- nos induce a pensar que se trata de otros merinos distintos de los merinos del rey, por ejemplo merinos de los tenentes, condición esta última que tenemos atestiguada para algunos de los merinos mencionados reiteradamente en estos años. Es el caso, por ejemplo, de Domingo Muñoz y Rodrigo Martínez, merinos de Poncio de Minerva y de Fernando Rodríguez en $1163^{71}$; de Domingo Juánez, que aparece entre 1164 y 1172, casi siempre en compañía de don Christiano, sin ninguna especificación ${ }^{72}$, pero a quienes un texto datado en octubre de 1170 nos permite encuadrar sin lugar a dudas en la categoría de merinos del tenente ${ }^{73}$. Lo mismo cabe pensar de Domingo Sánchez, quien sustituyó a Domingo Juánez al lado de don Christiano a partir de $1173^{74}$. A este gru-

67 Documento citado por C. ESTEPA, Estructura social, p. 448; Colección León, V, doc. no 1415; Colección Diplomática del Monasterio de San Vicente de Oviedo (años 781-1200), I parte, ed. P. FLORIANO LLORENTE, Oviedo, 1968, doc. no CLXXXIV y CXCIII.

68 M. RECUERO ASTRAY, Alfonso VII, pp. 145-147.

69 La última mención de Pedro Balzan como merino del rey en León data de 27 de noviembre de 1161; cfr. Colección Sahagún, IV, doc. $n^{\circ}$ 1339. Un año después ostentaba la mayordomía regia; cfr. Colección León, $V$, doc. ํㅜ 1518.

70 Excepcionalmente figura como "villicus regis" Nicholaus Frenarius en 1175 y en 1179 (Colección León, V, doc. no 1589 y 1610). En otras muchas ocasiones aparece, sin más, entre los otros merinos. Nada hace pensar que fuera un merino del rey.

71 1163. Abril 17: «Poncio de Minerua turres Legionis tenente. Dominico Munionis. Roderico Martini sub manu Fernandi Roderici et domni Poncii uillicantibus"; cfr. Colección León, V, doc. $n^{\circ} 1521$, La misma condición cabe atribuir a Pedro Arnaldi, quien, junto a Domingo Muñoz aparece como «uillicante» en 1162, cfr. en este mismo volumen, doc. $\mathrm{n}^{\mathrm{9}} 1516$ y 1517.

72 Colección León, V, doc. ํo 1531, 1539, 1542, 1543, 1556, 1557, 1562, 1563, 1564, 1569 y 1571.

73 1170. Octubre 24: «Fernando Roderici tenente turres in Legione, et cum germano eius Petro Roderici in eadem uilla dominante. Et Dominico lohanni et domno Christiano sub eis uillicantibus"; cfr. Colección León, V, doc. no 1559.

74 Colección León, V, doc. $n^{0} 1576,1577,1585$ y 1586. 
po de merinos pertenecían también Pedro León, Esteban Campsino y don Isidoro de Porta Episcopi ${ }^{75}$.

La misma situación persiste en principio durante el reinado de su hijo y sucesor. En época de Alfonso IX las fuentes documentales registran merinos en número variable, algunos presumiblemente subordinados a los tenentes, y otros a los que no podemos caracterizar con precisión ${ }^{76}$, pero que, en cualquier caso, nada tienen que ver -ni unos ni otros- con los merinos del rey que aparecían actuando regularmente en el distrito legionense por lo menos desde el reinado de Alfonso VI y que se mantuvieron hasta la muerte del Emperador.

Alfonso IX intentó no obstante el relanzamiento de la figura de los merinos del rey. Hecho que, creemos, es forzoso poner en relación con las graves dificultades económicas con que se encontró este monarca al llegar al Trono, derivadas de los despilfarros de rentas del reinado de Fernando $I /$ y agravadas por los abusos, con cargo a las rentas del patrimonio real, con motivo del cambio de reinado ${ }^{77}$, pues el núcleo fundamental de la actividad merinal era la recaudación de impuestos ${ }^{78}$. Ahora bien, sería más preciso hablar del relanzamiento de las atribuciones propias de este oficial del rey. Hacemos tal afirmación porque, después de la efímera aparición de Gonzalo Juánez y Pedro García en la tenencia de León ${ }^{79}$, los primeros tenentes de León en este reinado son al mismo tiempo merinos del rey en el distrito. No serían ajenas a esta solución, que por otra parte no era nueva, las presiones de la poderosa nobleza, siempre hostil a la figura de los merinos del rey, como quedará patente en el reinado de Alfonso X.

Salvo un breve paréntesis entre enero y abril de 1194, desde septiembre de 1189 y hasta febrero de 1195 Pedro Fernández de Benavides fue al mismo tiempo tenente

75 1180. Marzo 29: "Tenente Illas turres Legionensis Roi Cornelius. In eadem ciuitatem Petro Leone, et Stephanus Campsino et don Ysidori de Porta episcopi uillicantibus de manu de Dia Xemenez"; cfr. Colección León, $\mathrm{V}$, doc. $n^{\circ}$ 1616. En aquel momento Diego Jiménez era "senior» en León; cfr. en este mismo volumen, doc. $n^{\circ} 1612$.

76 Colección León, VI, ed. J.M. FERNÁNDEZ CATÓN, León, 1994, passim. Solamente en algún caso se hace constar su carácter de merinos de un tenente, v.g. 1194. Noviembre 25: «Petro Fernandi de Uaneuidas turres Legionis tenente et maiorino regis existente. Petrus Petri sub eo uillicante»; 1195. Junio 15: «Roderico Ordonii turres Legionis tenente et maiorino regis existente. Petro lohannis sub eo uillicante" (cfr. en este mismo volumen, doc. n 1713 y 1718). En ambos casos figuran a continuación otros merinos «uillicantibus in Legione», tal vez merinos del concejo.

77 J. GONZÁLEZ, Alfonso IX, I, Madrid, 1944, pp. 46 ss.; cfr. L. SUÁREZ FERNÁNDEZ y F. SUÁREZ BILBAO, "Historia política del reino de León (1157-1230)", en El reino de León en la Alta Edad Media, IV, La monarquia (1109-1230), León, 1993, pp. 286 ss. Hacen notar estos autores que en la curia celebrada en León entre marzo y abril de 1188 se aludió a los desórdenes que había que corregir.

78 J. MONTENEGRO, «La administración territorial», pp. 348 ss.

79 En mayo de 1189 se hallaba al frente de las torres de León Gonzalo Juánez y tres meses después aparece Pedro García como «tenens Legionem»; cfr. J. GONZÁLEZ, Alfonso IX, II, Madrid, 1944 , doc. $\mathrm{n}^{\circ} 21$ y 28. 
y merino del rey en León ${ }^{80}$. Le sustituyó en ambos cargos Rodrigo Ordóñez. Este magnate fue merino y tenente de las torres de León desde marzo de 1195, y como tal se mantuvo, como mínimo hasta mayo de $1196^{81}$. A partir de 1197 la tenencia de las torres y el ejercicio de la actividad merinal en León no confluyen en la misma persona, pero sospechamos que Rodrigo Ordóñez continuó, y por lo menos hasta el año 1204, ejerciendo las tareas propias del merino del rey en el distrito. Así parece desprenderse de algunos documentos de la catedral de León ${ }^{82}$. Existen, por otra parte, indicios como para pensar que ambos personajes -Pedro Fernández de Benavides y Rodrigo Ordóñez- fueron, además, los primeros merinos mayores del reino de León.

Seguramente a Rodrigo Ordóñez le sucedieron en el cargo de merino del rey en León Pelayo Martín y Suero Martínez $z^{83}$. Por estas fechas Suero Gallego era «maiorinus in totis Asturiis ${ }^{84}$. Pero a partir de estos años cesan las menciones a los merinos del rey, que sólo reaparecen tímidamente en los últimos años de este reinado, seguramente porque la alta nobleza consiguió imponerse. Se trata de una conclusión provisional que habrá que confirmar mediante el análisis comparativo con lo que ocurrió en otras demarcaciones del reino de León, pero en principio es llamativo que la ausencia de menciones a merinos del rey en los diplomas de Alfonso IX, coincida en el tiempo con la ausencia de menciones a merinos del rey en León, lo que desde nuestro punto de vista parece una señal inequívoca del nuevo retroceso en el reino de León de estos oficiales.

En conclusión, parece que a raíz de la división de los reinos, a la muerte de Alfonso VII, en León se oscureció el papel de los merinos del rey. Hubo un intento de relanzar esta figura en tiempos de Alfonso IX, pero no llegó a consolidarse, debido a la escasa simpatía por parte de la nobleza magnaticia hacia unos oficiales claramente potenciadores del poder del rey.

80 Colección León, VI, doc. $\mathrm{n}^{\mathrm{0}}$ 1681, 1684, 1686, 1687, 1689, 1690, 1695, 1698, 1704, 1705, 1709, 1712, 1713, 1714 y 1715; J. GONZÁLEZ, Alfonso IX, II, doc. ํํ 57, 67, 70, 81 y 89 . Por estos años actuaba un merino del rey en Galicia y otro en Zamora y Toro; cfr. J. GONZÁLEZ, Alfonso IX, II, doc. $\mathrm{n}^{2} 86,87,91$ y 95 .

81 J. GONZÁLEZ, Alfonso IX, II, doc. ำ 95, 97 y 99; Colección León, VI, doc. no 1716, 1717, $1718,1720,1721,1722,1724,1725,1726$ y 1727 . Merced a uno de estos documentos, el $n^{\circ} 1725$, una copia de un diploma, sabemos que Rodrigo Ordóñez era también merino de Asturias, y sospechamos que también lo fue en su momento Pedro Fernández de Benavides, lo que explica que un diploma de Alfonso IX datado en 1192 consigne a Pedro Fernández como «...regis merino a Villa Uxo usque ad Dorium»; J. GONZÁLEZ, Alfonso IX, II, doc. $\mathrm{n}^{\circ} 55$.

82 Colección León, VI, doc. nº 1776 y 1777.

83 Pelayo Martín aparece como merino del rey a continuación del tenente de las torres de León entre abril de 1207 y febrero de 1208; cfr. Colección León, VI, doc. nº 1793 y 1800 y J. GONZÁLEZ, Alfonso IX, II, doc. no 223 y 224. Suero Martínez figura como merino del rey en junio de 1214; cfr. Colección León, VI, doc. $\mathrm{n}^{\mathrm{0}}$ 1834-1836.

84 1215: "Suario Galleco maiorinus in totis Asturiis»; cfr. J. GONZÁLEZ, Alfonso IX, II, doc. $n^{\circ} 315$. 